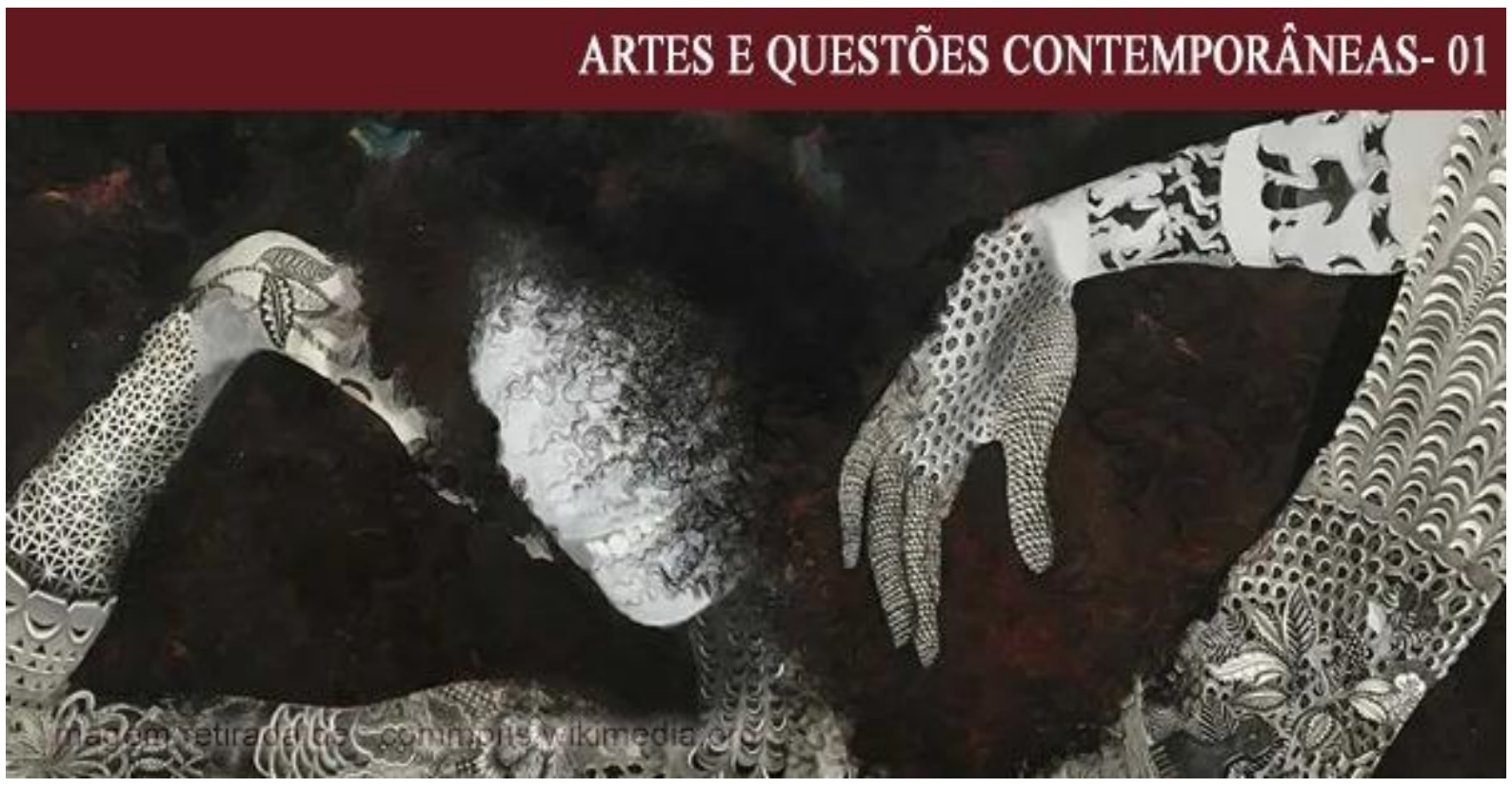

\title{
VAGINA DA ARTISTA - PERFORMANCE FEMINISTA EM POÉTICAS DE DUAS ARTISTAS MULHERES
}

\author{
Renata Andrea Santana de Lucia \\ ORCID: https://orcid.org/0000-0002-7163-425X. \\ E-mail: renatadeluccia@gmail.com. \\ João Paulo Baliscei \\ ORCID: https://orcid.org/0000-0001-8752-244X. \\ E-mail: jpbaliscei@uem.br.
}

Resumo: O artigo tem como objetivo problematizar a performance enquanto prática artística que promove a resistência, a pluralidade e a diferença, discutindo como ela pode favorecer aspectos educativos. Apresenta o conceito de performance em seus aspectos históricos, antropológicos e artísticos, bem como a performance autobiográfica, que possibilita o resgate de experiências pessoais, memórias coletivas e, no recorte apontado aqui, o exercício do ativismo feminista. Aborda aspectos do movimento feminista e analisa performances de duas artistas mulheres e feministas: a artista norte-americana Carolee Schneemann e a artista brasileira Panmela Castro. Por fim, avalia o caminho evocado pela performance como viável ao estabelecimento de estratégias de resistência e sensibilização por meio da experiência artística compartilhada entre performer e espectadoras. Ademais, aponta a performance como alternativa para instigar o pensamento crítico, a liberdade e a criação de possibilidades de transformações no âmbito pessoal e coletivo, por meio de ações que abordam temáticas identitárias que refletem as lutas de movimentos sociais, como o movimento feminista, movimento negro e movimento LGBTQI+.

Palavras-chave: Arte contemporânea. Performance. Performance autobiográfica. Feminismo. Mulheres artistas.

\section{ARTIST'S VAGINA - FEMINIST PERFORMANCE ON POETICS OF TWO FEMALE ARTISTS}

Abstract: The article aims to problematize performance as an artistic practice that promotes resistance, plurality and difference, discussing how it (the performance) can favor educational aspects. This paper presents the concept of performance in its historical, anthropological and artistic aspects, as well as the autobiographical performance, which enables the recovery of personal experiences, collective memories, and, in the clipping pointed here, the exercise of feminist activism. The article also addresses aspects of the feminist movement and analyzes the performances of two women and feminist artists: US artist Carolee Schneemann and Brazilian artist Pammela

\section{POLÊM!CA $\mid$ LABORË}

Polêmica - Revista Eletrônica da Uerj - Rua São Francisco Xavier, 524, $1^{\circ}$ andar bloco D, sl.1001 • Tels.: +55 21 2334-4088 / 4087 • http://www.e-publicacoes.uerj.br/index.php/polemica/index http://www.labore.uerj.br • laboreuerj@yahoo.com.br 
Castro. Finally, it evaluates the path evoked by the performance as feasible for the establishment of resistance and sensitization strategies through the shared artistic experience between performer and spectators. In addition, the article points to performance as an alternative to instigate critical thinking, freedom, and the creation of possibilities for transformations at both the personal and collective levels, through actions that address identity themes which reflect the struggles of social movements, such as the feminist movement, the black movement, and the "LGBTQI+" movement.

Keywords: Contemporary art. Performance. Autobiographical Performance. Feminism. Women Artists.

\section{Introdução}

Em 2016, a partir do golpe institucional com o impeachment da presidenta ${ }^{1}$ Dilma Rousseff, o Brasil enfrentou um aprofundamento da crise sociopolítica e econômica bem como um agravamento das condições da população brasileira, com graves perdas de direitos e ameaça ao estado democrático de direito, como a aprovação da reforma trabalhista e da PEC 241/55, conhecida como PEC dos gastos públicos. O resultado disso é a intensificação da desigualdade social e, consequentemente, da violência.

Aliado a isso, o Brasil presenciou o crescimento de uma onda conservadora respaldada por um discurso religioso e cristão, que dissemina ódio contra tudo aquilo que diz respeito às garantias dos direitos civis das minorias sociais, como as mulheres, as pessoas indígenas, as negras, as quilombolas, as $\mathrm{LGBTQI}^{2}$, as populações pobres, dentre outros grupos populacionais que têm conquistado significativos (porém ainda insuficientes) avanços sociais na luta pela equidade de direitos.

Esse retrocesso se intensificou nas últimas eleições presidenciais, como foi apontado pelo mapeamento da violência política publicado por Haroldo Ceravolo e Lucas Berti (2018), no site Ópera Mundi. O estudo contabilizou os casos notificados de violências, entre elas agressões físicas e morais, lesão corporal, assassinatos, estupros, pichações, cometidas por eleitores que se declararam apoiadores do atual presidente. A última atualização até a produção deste artigo foi o assassinato do colaborador da Funai, Maxciel Pereira dos Santos, em 06 de setembro de 2019, em Tabatinga (AM), na fronteira com Peru e Colômbia - o que, reunido a outros, atinge um total de 200 casos de violência política registrados pelo mapeamento.

$\mathrm{O}$ aumento da violência política se relaciona com a disseminação de preconceitos em nome da ideia de normatização, controle e ordem, respaldada por um discurso cristão e

\footnotetext{
${ }^{1}$ A escrita deste artigo é tecida por meio da escolha linguística e política de enfatizar artigos, pronomes e substantivos femininos, de modo a valorizar a linguagem inclusiva de gênero.

${ }^{2}$ Lésbicas, Gays, Bissexuais, Transsexuais, Travestis, Transgêneros, Queer, Interssexuais e outras possíveis identidades de gênero.
}

\section{POLÊM!CA $\mid$ LABORE}

Polêmica - Revista Eletrônica da Uerj - Rua São Francisco Xavier, 524, $1^{\circ}$ andar

bloco D, sl.1001 • Tels.: +55 21 2334-4088 / 4087 • http://www.e-publicacoes.uerj.br/index.php/polemica/index

http://www.labore.uerj.br • laboreuerj@yahoo.com.br 
associada à (bem-sucedida) estratégia de divulgação de informações falsas ${ }^{3}$ pelas redes sociais, com o intuito de causar histeria coletiva em parte da população brasileira. Considera-se que essa mesma parcela da população que apóia torturadores, banaliza e generaliza a violência e acaba, direta ou indiretamente, por estimular a morte do diferente quando, por exemplo, critica os direitos humanos ou sai às ruas para pedir intervenção militar.

Esse conservadorismo é pensado como um movimento inevitável de reação à visibilidade que as populações que sempre foram marginalizadas começaram a ter ao ocupar espaços sociais públicos, reafirmar sua existência e lutar contra os privilégios de umas em detrimento de outras. Avalia-se que essa onda conservadora se torna um risco numa sociedade como a brasileira, com tanta desigualdade, e cuja parte significativa da população não tem acesso aos direitos humanos básicos, como educação, seguridade social, proteção básica e saúde e, por isso, precisa lutar diariamente pela sobrevivência, tornando-se alvos fáceis de manipulação de massa.

Uma breve análise de dados sobre o acesso à educação nos dá um panorama da situação. No Brasil, estima-se que $11,1 \%$ da população não tem praticamente nenhuma instrução escolar e apenas $13 \%$ das pessoas brasileiras acessam o ensino técnico e superior, sendo que apenas $30,7 \%$ da população adulta completa o ensino médio (IBGE, 2015). Isso significa que em torno de $70 \%$ da população brasileira não completa o ciclo da Educação Básica. Esse cenário tende a piorar com as medidas de austeridades alavancadas a partir do golpe já referido, e fortalecidas no e pelo atual governo - que recentemente anunciou um profundo corte no setor da cultura e educação, assim como anteriormente havia proposto reduzir verba para cursos de filosofia e sociologia no país (FOLHA DE SÃO PAULO, 2019).

Essas e outras ações neoliberais de ataques às políticas públicas, em especial à cultura e educação, remetem à análise de Darcy Ribeiro ${ }^{4}$, em 1977, que aponta: “a crise da educação no

\footnotetext{
${ }^{3}$ As informações falsas, denominadas fake news, utilizam as tecnologias disponíveis para manipular a opinião pública. No Brasil, durante o ano eleitoral, houve um intenso uso desta estratégia, que afetou os resultados nas urnas. Como em março de 2018, por exemplo, quando a vereadora Marielle Franco foi brutalmente assassinada no Rio de Janeiro $(\mathrm{G} 1,2018)$ e, em menos de 48 horas após o crime, boatos se disseminaram nas redes sociais sobre seu suposto envolvimento com traficantes. Segundo Almeida (2018), um estudo da Diretoria de Análise de Políticas Públicas da Fundação Getúlio Vargas (FGV DAPP) apontou que, a partir de um único post de um deputado na plataforma social Twitter, outros 2,1 milhões de posts foram publicados com o conteúdo difamatório, viralizando o factoide por cerca de 24 horas nas redes sociais, até que novos tuites se propagaram, desmentindo a fake news.

${ }^{4}$ Darcy Ribeiro proferiu a famosa frase sobre educação durante uma palestra, chamada por ele de "SOBRE O OBVIO".
}

\section{POLÊM!CA $\mid$ LABORE}

Polêmica - Revista Eletrônica da Uerj - Rua São Francisco Xavier, 524, $1^{\circ}$ andar

bloco D, sl.1001 • Tels.: +55 21 2334-4088 / 4087 • http://www.e-publicacoes.uerj.br/index.php/polemica/index http://www.labore.uerj.br • laboreuerj@yahoo.com.br 
Brasil não é uma crise, é um projeto" (apud SOUZA, 2018, não paginado). Assim, é limitado o acesso da população à educação pública e de qualidade a fim de impedir a formação de pessoas cidadãs críticas e conscientes de seu contexto sócio-histórico e cultural.

Por isso é avaliada a urgência de construir estratégias de resistência, de disseminação de informações de qualidade, de sensibilização por meio da Arte e da educação, para que o povo se distancie ou transforme a ignorância em conhecimento e se levante contra as desigualdades e opressões sofridas. O conhecimento é uma arma muito poderosa para a emancipação das pessoas, como disse Bertold Brecht, em Elogio do Aprendizado:

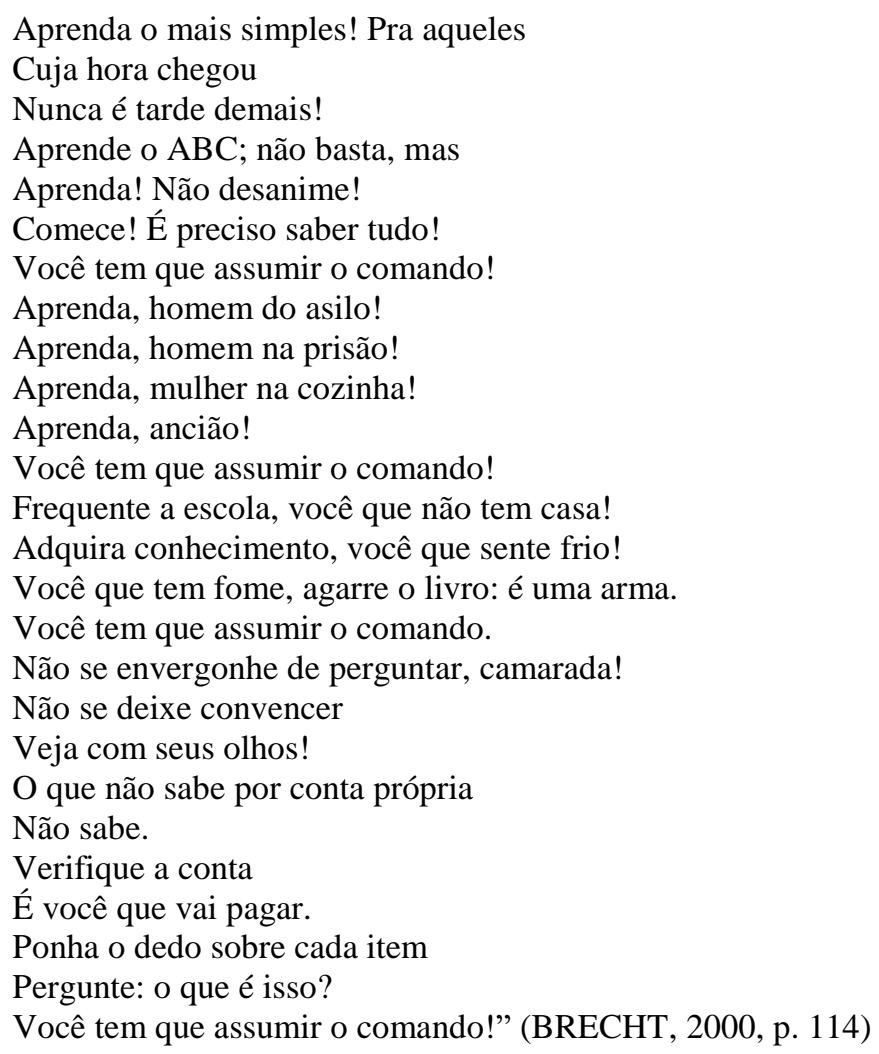

O pensamento crítico almejado por Brecht (2000) pode se fortalecer com a educação e é construído a partir das experiências, da maneira como se assimila o mundo. A Arte, por sua vez, desempenha um importante papel educativo na busca por essa emancipação do pensamento, na medida em que promove experiências que estimulam e desenvolvem a sensibilidade, a criatividade e a criticidade.

É importante destacar que o estudo da Arte não aparece descolado da realidade e da história. Como aponta Ana Mae Barbosa (1989), a Arte é fruto da imaginação, mas existe em comunhão com a economia, política e padrões sociais determinados pelo contexto onde está

\section{POLÊM!CA | LABORẸ}

Polêmica - Revista Eletrônica da Uerj - Rua São Francisco Xavier, 524, $1^{\circ}$ andar bloco D, sl.1001 • Tels.: +55 21 2334-4088 / 4087 • http://www.e-publicacoes.uerj.br/index.php/polemica/index http://www.labore.uerj.br • laboreuerj@yahoo.com.br 
inserida. Há uma dimensão histórica que não pode ser negada e que permite estabelecer “"[...] conexões entre outras obras de Arte e outras manifestações culturais" (BARBOSA, 1989, p. 178) - o que confere ao saber artístico a potência de conhecer outras culturas e ampliar os saberes acerca da história da humanidade.

Ainda, é fundamental entender o tempo-espaço ocupado pela artista, bem como seus valores estéticos. Para ela, entender essa dimensão histórica inevitavelmente proporcionará uma compreensão acerca de si mesma, do seu tempo histórico e da cultura na qual está inserida, permitindo que a criação artística também produza signos críticos acerca desse contexto.

Para a construção do pensamento artístico é importante, dentre outras coisas, o reconhecimento da história da Arte em suas múltiplas culturas, exercícios de análise de imagens, a busca de referências artísticas e aprofundamento na compreensão de signos e símbolos. Logo, a leitura de imagens cotidianas é importante para ampliar o repertório visual, auxiliar na interação com o mundo de modo a favorecer o processo de construção de um olhar crítico e atento sobre a realidade e, inclusive, para identificar e contestar o que reforça preconceitos, desigualdades e opressões, como temos defendido em outra pesquisa (BALISCEI, 2020). Nela, compartilhamos um conjunto de procedimentos que orientam àquilo que nos referimos como investigações visuais críticas e performativas, exercício esse que supõe que as imagens não são apenas artefatos estéticos e plásticos, cujos elementos formais são passíveis de leitura, mas, também, artefatos políticos e identitários a partir dos quais grupos disputam por representações, e a partir dos quais, muitas vezes, as diferenças são reduzidas a estereótipos.

Por meio de imagens óbvias [os estereótipos] essas representações visuais simplificam as diferenças, ajustando-as conforme os valores, estéticas e interesses hegemônicos e contribuem para constituir fronteiras simbólicas - a partir das quais o "abjeto" é separado da "norma". [...] estereotipar pode ser compreendido como economizar detalhes, apagar arestas, anular diferenças e evidenciar hierarquias (BALISCEI, 2020, p. 69).

No que diz especificamente à Arte Contemporânea, sobretudo à performance, tomamos a posição de que ela produz imagens que podem evidenciar e problematizar os estereótipos representacionais além de reforçar essa potência política intrínseca à visualidade. É nela que, por vezes, artistas tratam de temáticas identitárias que refletem as lutas de movimentos sociais travadas desde meados do século XX, como o movimento feminista, movimento negro, movimento LGBTQI+, dentre outros. A hipótese é de que a performance contribui para a aceitação e valorização da existência de corpos políticos, para a problematização de contextos

\section{POLÊM!CA | LABORẸ}

Polêmica - Revista Eletrônica da Uerj - Rua São Francisco Xavier, 524, $1^{\circ}$ andar

bloco D, sl.1001 • Tels.: +55 21 2334-4088/4087 • http://www.e-publicacoes.uerj.br/index.php/polemica/index http://www.labore.uerj.br • laboreuerj@yahoo.com.br 
sócio-históricos e culturais, e para evocar a potência de ação e transformação por meio da Arte (SOUZA, 2019).

A performance modifica a experiência ordinária do cotidiano e promove caminhos de descobertas das potências de corpos políticos que ocupam este e outros espaços. Na Arte, o corpo da artista se torna seu próprio objeto de criação. Corpo político aqui é entendido como aquele que pertence e ocupa um espaço social, aonde expressa e significa sua existência, ou seja, às "várias maneiras como o corpo mostra ou produz sua significação cultural" (BUTLER, 2003, p. 201).

Para abordar as questões propostas neste artigo, como corpo político, identidade, autoimagem e sujeito social, além de questões sociais, culturais, éticas e políticas, é necessário entender uma das especificidades da performance: a autobiográfica. Segundo Ana Bernstein (2010), ela estabelece uma relação intersubjetiva entre a artista e seu processo criativo, de modo que o (seu) corpo assume o lugar de representação ao mesmo tempo em que se emprega material autobiográfico. Ainda, desempenha uma “[...] função crítica na criação de um espaço discursivo para minorias que não se enquadram na normatividade do discurso ideológico dominante" (BERNSTEIN, 2010, p. 92). Deste modo, a performance autobiográfica se torna instrumento artístico e político que evidencia a potência da performer como agente social. Ainda, ultrapassa os limites pré-estabelecidos no campo artístico, estético, narrativo, poético e cotidiano, além de promover um espaço suspenso que subverte sentidos naturalizados, para romper com a zona de conforto.

Bom-Tempo (2014) explica que as ações performáticas problematizam os limites colocados para os contextos de vida, trazem aberturas e provocam fissuras para promover uma educação que, ao mesmo tempo, desaloja estagnações de signos fixados pela cultura e reflete sobre os significados disparados pela arte performática. Por isso é importante provocar novos e potentes encontros, que favoreçam a desestabilização e resultem em novas trajetórias e modos de existência.

Mediante ao exposto, o presente artigo tem como objetivo destacar a performance como prática artística que promove a resistência, a pluralidade e a diferença. Para atingi-lo, propõe analisar obras de artistas mulheres que apresentam temáticas vinculadas à vivência do feminino, com questões relacionadas as intersecções de gênero, classe, sexualidade, raça, violências e outras questões evocadas pelo movimento feminista, relacionadas.

\section{POLÊM!CA | LABORẸ}

Polêmica - Revista Eletrônica da Uerj - Rua São Francisco Xavier, 524, $1^{\circ}$ andar

bloco D, sl.1001 • Tels.: +55 21 2334-4088 / 4087 • http://www.e-publicacoes.uerj.br/index.php/polemica/index

http://www.labore.uerj.br • laboreuerj@yahoo.com.br 
Para aprofundar a reflexão, o artigo aborda aspectos históricos, antropológicos, artísticos da performance, bem como a questão da autobiografia e a importância do trabalho com objetos, memórias e imagens, para ampliar a consciência individual e coletiva. Seleciona e analisa, por fim, algumas produções em performance com viés feminista, da artista americana Carolee Schneemann e da artista brasileira contemporânea Panmela Castro.

\section{A performance na Arte}

A performance estabelece um processo artístico aberto, mutante, sujeito a interferências inusitadas, que se materializa no tempo-espaço da ação artística e na relação entre a performer e a espectadora. Mais do que um produto terminado, estático e eterno, o que importa é a experiência provocada pela ação artística e a instauração da presença no ato performativo.

Por ser um conceito amplo, qualquer comportamento, evento, ação ou coisa pode ser estudado e analisado como performance (SANTOS, 2011), já que ela pode ser reconhecida no cotidiano como um evento destacado pelo estranhamento causado pela experiência. Richard Schechner ${ }^{5}$ inclui em seu conceito de performance todos os domínios da cultura e lhe confere um caráter universal, pois compreende sua amplitude, enquanto Féral a descreve como “[...] todas as formas de manifestações teatrais, rituais, de divertimento e toda manifestação do cotidiano, desde práticas esportivas, festejos populares, jogos, cinema, rituais e cerimônias religiosas" (FÉRAL, 2008, p. 198).

Abarcar tantas manifestações culturais e artísticas sob o mesmo conceito pode gerar um significativo problema no campo da Arte, visto que se corre o risco de diluir o entendimento e a eficácia do conceito, como aponta Josette Féral (2008) em seu estudo sobre a performatividade. Para evitar tal risco, consideramos ser importante aprofundar o entendimento sobre a performance na Arte.

As primeiras manifestações artísticas reconhecidas como performance partiram de artistas visuais que buscavam encontrar uma nova trajetória, de natureza versátil e híbrida, com manifestações de diversas linguagens artísticas justapostas na composição da obra, materializada no tempo e espaço presentes.

\footnotetext{
${ }^{5}$ Diretor de teatro, pesquisou o conceito de performance na década de 70, aliado a estudos antropológicos sobre a temática.

\section{POLÊM!CA $\mid$ LABORẸ}


Roselee Goldberg (2006) indica que a performance é uma forma de expressão artística cujo manifesto é ilimitado, visto que cada performer define o próprio processo de execução. Neste sentido, expande as fronteiras da criação, pois seu processo é livre, definido pelas necessidades criativas de cada artista e com os elementos necessários para a ação proposta e, mais além, para sua vida. Portanto, não prescinde necessariamente de técnicas artísticas específicas ou predeterminadas para orientar seu fazer, como acontece por vezes no teatro, na música e nas artes visuais - linguagens cujas histórias foram marcadas pela validação a partir das técnicas empregadas.

Segundo Renato Cohen (2007), a performance é um gênero artístico complexo que busca romper com convenções estabelecidas, numa tentativa de artistas estabelecerem uma nova relação dinâmica e espacial com a Arte, na qual seu próprio corpo torna-se seu objeto artístico. Esse rompimento, com a renovação da linguagem tradicional de artistas do teatro, da música e das artes visuais, está diretamente relacionado com o contexto das vanguardas artísticas (especialmente o Futurismo, o Dadaísmo, o Surrealismo e a Bauhaus), que negavam a representação da realidade, as convenções formais e estéticas, de modo que refletissem as intensas transformações ocorridas até meados do século XX.

Para Jorge Glusberg (2009), a performance se concretiza na experiência compartilhada entre performer e espectadora/espectador, numa relação empática e dinâmica, cujo movimento de consciência é em parte da performer, que mostra a ação a ser recebida por quem vê, e este, que propõe interpretações por conta própria, a partir de sua visão de mundo. O valor da Arte está nesse encontro, que corrobora questões presentes nas vanguardas artísticas e nas experiências artísticas contemporâneas.

Assim, é uma manifestação artística que existe num tempo-espaço delimitado pela artista, acontece e se transforma no ato-processo, sendo aberta para a participação das pessoas espectadoras. Elas também performam, pois estão situadas na intimidade da ação e são afetadas por seu imediatismo ou pelos riscos implicados no jogo. Deixam-se levar pela performatividade da artista, por suas ações executadas (FÉRAL, 2008). Porém, é preciso explicar, assim como adverte Josette Féral (2008): as pessoas podem se colocar em seu exterior e garantir o direito de olhar de fora, de perceber a obra sem integrá-la.

Entendida como um processo artístico aberto, mutante e sujeito a interferências inusitadas, é um gênero artístico que propõe uma Arte emancipada e tem um caráter anárquico, como aponta Renato Cohen (2007), abriga abriga artistas de diversas linguagens, de modo que

\section{POLÊM!CA $\mid$ LABORẸ}

Polêmica - Revista Eletrônica da Uerj - Rua São Francisco Xavier, 524, $1^{\circ}$ andar

bloco D, sl.1001 • Tels.: +55 21 2334-4088/4087 • http://www.e-publicacoes.uerj.br/index.php/polemica/index http://www.labore.uerj.br • laboreuerj@yahoo.com.br 
"[...] essa 'babel'" das artes não se origina de uma migração de artistas que não encontram espaço nas suas linguagens, [...] se origina da busca intensa, de uma arte integrativa, uma arte total, que escape das delimitações disciplinares" (COHEN, 2007, p. 50).

Um dos procedimentos de ruptura encontrados na Arte Contemporânea, em especial na performance, é a não-hierarquia entre linguagens artísticas. Já não há mais o interesse absoluto por autora, texto, música, objeto de Arte em si, e tampouco a durabilidade e eternidade daquilo que se produz, mas sim o evento e a experiência que são provocados. A obra Alma. Silueta en fuego (Silueta de cenizas), de 1975, que integra a série Siluetas (1973-1980), da artista cubana Ana Mendieta, é exemplo desta não-hierarquia. Ela é composta por uma série de elementos interligados e interdependentes de modo que cada um assume a sua função semântica na totalidade, desde o corpo e silhueta impressa da artista, a ação realizada, a paisagem, a passagem do tempo, os elementos naturais utilizados, até o resultado final, na forma de fotografias e vídeos que registraram o evento. Em todas as imagens está a silhueta da artista, impressa na terra e coberta por um molde de papelão revestido por tecidos brancos. O molde e a silhueta que ele representa vão sendo consumidos pelo fogo.

Ana Mendieta utilizava a fotografia e o vídeo como meios de registro e apresentação de suas obras, uma tentativa de mostrar questões relativas à extradição pela qual passou ainda durante a infância, quando foi levada de Cuba para os EUA. Lá ela passou a viver numa realidade radicalmente diferente de sua terra natal e, dessa experiência de deslocamento, distanciamento e diferença tão marcante, Mendieta encontrou na Arte lugares com os quais pudesse se reconhecer e tornar sua vida possível (FRANCISQUETTI, 2009).

Portanto, a busca da pessoa que performa está na vivência de uma autotransformação promovida pela Arte, de modo que seja possível alcançar e modificar a experiência ordinária da vida daquelas que se encontram no ato performativo. Féral (2008) entende a performance como uma forma de superar ou ultrapassar os limites de um padrão, ou que se engaja num espetáculo, jogo ou ritual, estando sujeita, ao menos, às três operações:

1. ser/estar ("being"), ou seja, se comportar ("to behave");

2. fazer ("doing"). É a atividade de tudo o que existe, dos quarks aos seres humanos;

\footnotetext{
6 "Babel" como metáfora para ações artísticas sobrepostas, interligadas e diferentes. Diferentemente da babel bíblica, cuja diferença na linguagem é responsável pela confusão divina, na performance é interessante que elementos diversos, expressos em corpos, idiomas, ações, materiais, registros múltiplos, sejam inteligíveis aos demais.
}

\section{POLÊM!CA $\mid$ LABORÉ}

Polêmica - Revista Eletrônica da Uerj - Rua São Francisco Xavier, 524, $1^{\circ}$ andar bloco D, sl.1001 • Tels.: +55 21 2334-4088 / 4087 • http://www.e-publicacoes.uerj.br/index.php/polemica/index http://www.labore.uerj.br • laboreuerj@yahoo.com.br 
3. mostrar o que faz ("showing doing", ligado à natureza dos comportamentos humanos). Este consiste em dar-se em espetáculo, em mostrar (ou se mostrar). (FÉRAL, 2008, p. 200).

Essas três operações estão presentes no processo criativo de muitas/os artistas e evocam a noção de performatividade (relacionada à execução de uma ação, anterior a qualquer sentido de representação). Para Féral (2008), a performatividade valoriza o processo, a presença de artista e de elementos que compõem a obra, além da participação direta de pessoas espectadoras e de um diálogo entre diversas linguagens artísticas.

\section{O estudo autobiográfico e o feminismo na performance}

As raízes da performance autobiográfica se encontram na década de 1970, quando esta linguagem artística se lançou enquanto instrumento de crítica social, relacionada às necessidades daquelas/es excluídos por raça, gênero ou classe. Consideramos a pesquisa autobiográfica a partir deste recorte histórico, mas não ignoramos as diversas abordagens da experiência pessoal na expressão artística.

De acordo com Marvin Carlson (2010, p. 163), a performance autobiográfica é aquela "[...] envolvida com as preocupações, os desejos e mesmo a visibilidade dos normalmente excluídos [...] [cuja] área mais elaborada e desenvolvida de tal performance, envolve performance de mulheres". O posicionamento do autor pode ser relacionado ao fortalecimento do movimento feminista da segunda onda na década de 70 , no contexto de crescente insatisfação com a condição da mulher na sociedade, ou seja, concomitante ao desenvolvimento da teoria feminista, na qual as mulheres passaram a questionar seu papel social e a imposição da lógica patriarcal sobre seus corpos e suas histórias.

O movimento feminista iniciou efetivamente sua luta nas últimas décadas do século XIX, com a luta organizada das inglesas pelo direito de voto, que se concretizou nas primeiras décadas do século seguinte. Anteriormente, muitas mulheres do Ocidente já haviam contestado seu lugar na sociedade, mas sem uma organização política efetiva, como na Idade Média quando mulheres que não aceitavam os dogmas da Igreja Católica eram condenadas pela Inquisição. Mesmo com a conquista do direito ao voto nos países ocidentais, o movimento feminista perdeu força e só voltou a se destacar a partir da década de 1960, especialmente na Europa e nos Estados Unidos. As mulheres passaram a apontar, então, para questões relativas ao espaço da mulher na sociedade, seja no trabalho, na vida pública, na educação, assim como criticaram as

\section{POLÊM!CA $\mid$ LABORE}

Polêmica - Revista Eletrônica da Uerj - Rua São Francisco Xavier, 524, $1^{\circ}$ andar

bloco D, sl.1001 • Tels.: +55 21 2334-4088 / 4087 • http://www.e-publicacoes.uerj.br/index.php/polemica/index http://www.labore.uerj.br • laboreuerj@yahoo.com.br 
relações de poder existente entre homens e mulheres, de modo que estas tivessem liberdade e autonomia para decidir sobre suas vidas e seus próprios corpos (PINTO, 2010).

Nesse contexto de acentuada efervescência cultural e política na história ocidental, houve um rápido crescimento em torno do pensamento e das atividades feministas, o que influenciou diretamente a Arte e refletiu no destaque de uma gama de artistas-performers (mulheres que levavam a luta do feminismo para a expressão estética).

Carlson (2010) destaca que no início dos anos 1970, o fortalecimento do movimento das mulheres favoreceu o clima para as produções de artistas-performers, que abordavam em suas obras questões relacionadas à identidade, à autoimagem e ao eu social, preocupadas em dar visibilidade para suas experiências privadas e públicas, bem como problematizar a situação das mulheres na sociedade e na história. Segundo Carlson (2010, p. 170), a performance de cunho feminista "[...] tem sido mais uma coisa psicológica, social e política sobre o que significa ser uma mulher nessa sociedade, uma mulher particular, uma artista".

É importante analisarmos que, mesmo que apontasse para questões particulares, a performance autobiográfica sempre demonstrou uma preocupação com questões sociais e políticas mais abrangentes, mantendo o caráter crítico ao mesmo tempo em que se consolidava enquanto uma Arte contestadora do rigor estético e formal de seu tempo histórico, de modo a ampliar a relação de artistas com a Arte.

Carlson (2010) considera arte autobiográfica de artistas-performers mulheres sujeitas a três distintas orientações: as experiências pessoais, as memórias coletivas e o ativismo feminista. Para apresentá-las, optamos exemplificar com obras de duas artistas mulheres, Carolee Schneemann e Panmela Castro, que abrangem essas orientações.

Carolee Schneemann, artista norte-americana, é uma referência no campo da pesquisa autobiográfica que aborda temáticas feministas e também evoca memórias coletivas, relacionadas às questões de corpo, sexualidade e gênero. Com produções em pintura, instalações, fotografia, cinema e, principalmente, performance - nas quais explorava propostas estéticas inovadoras - começou sua trajetória artística no contexto de afirmação do feminismo.

Na década de 1960, fez happenings, como Meat Joy [Prazer da Carne] em 1964, no qual promoveu "um rito erótico com sentido comunitário, apontando a dimensão coletiva da existência sexual; em celebração da carne, Schneemann usa o sangue de carcaças de animais para lambuzar os corpos dos participantes" (MATESCO, 2014). Porém, somente a partir de 1990 que seu trabalho passou a ser reconhecido como importante para a Arte feminista. Antes

\section{POLÊM!CA $\mid$ LABORẸ}

Polêmica - Revista Eletrônica da Uerj - Rua São Francisco Xavier, 524, $1^{\circ}$ andar

bloco D, sl.1001 • Tels.: +55 21 2334-4088 / 4087 • http://www.e-publicacoes.uerj.br/index.php/polemica/index http://www.labore.uerj.br • laboreuerj@yahoo.com.br 
disso, era tida como narcisista com expressividade excessivamente sexualizada (MOLINA, 2014).

Uma das obras mais conhecidas da artista é Interior Scroll (1975) [Pergaminho Interior], na qual se coloca nua em cima de uma mesa, após pintar seu corpo com tinta. Então desenrola de sua vagina um pergaminho, enquanto lê em voz alta o texto registrado nele. No texto, a artista reage à uma crítica recebida de um cineasta estruturalista, que afirmava ser impossível olhar para os filmes da artista '[...]que citavam sua 'confusão pessoal', sua 'persistência de sentimentos', sua 'sensibilidade ao toque manual', sua 'indulgência diária' e suas 'técnicas primitivas"” (CARLSON, 2010, p. 170). Deste modo, reduzia a importância estética e política da Arte de Carolee Schneemann.

A ação da artista confrontava os estereótipos masculinos fetichistas com relação ao nu feminino, especialmente à vagina, cuja invisibilidade reclamada socialmente reforça o pensamento machista, falocêntrico e misógino. A vagina exposta na obra de Schneemann atravessa o discurso masculino de modo a subvertê-lo, de transmutar o lugar dado para a nudez feminina, inclusive na Arte, e tirá-la do aspecto erótico (o corpo-objeto de prazer) ou sagrado (o corpo que produz vida), e colocá-la num lugar de enfrentamento, de força e coragem, no lugar da denúncia da violência de gênero.

Apesar de haver uma questão pessoal em foco, nessa e em outras ações, a artista aponta para uma crítica à postura masculina de entender a demanda feminina em termos estéticos, conceituais e políticos. A ação é permeada de erotismo que se contrasta com força das palavras escritas e lidas pela artista em forma de ironia e denúncia, como apresenta o fragmento do texto a seguir:

[...] (não aceito conselhos

de homens que só falam

consigo mesmos)

PRESTE ATENÇÃO À LINGUAGEM

CINEMATOGRÁFICA CRÍTICA E PRÁTICA

ELA SÓ EXISTE PARA E EM

UM GÊNERO SEXUAL

$[\ldots]$

o meu trabalho não tem significado além

da lógica de seus sistemas

eu eliminei

emoção intuição inspiração -

esses hábitos engrandecidos que

distinguem os artistas das

pessoas comuns - essas

tendências indefinidas que

\section{POLÊM!CA $\mid$ LABORÉ}

Polêmica - Revista Eletrônica da Uerj - Rua São Francisco Xavier, 524, $1^{\circ}$ andar

bloco D, sl.1001 • Tels.: +55 21 2334-4088 / 4087 • http://www.e-publicacoes.uerj.br/index.php/polemica/index

http://www.labore.uerj.br • laboreuerj@yahoo.com.br 


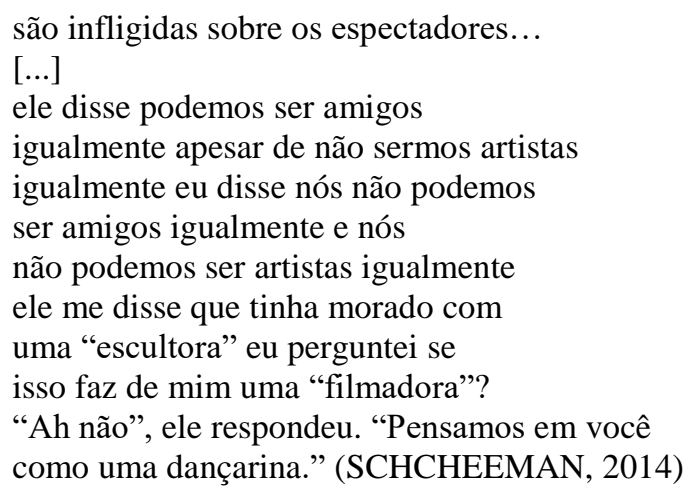

Em Interior Scroll, Carolee Schcheeman revela também anseios do movimento feminista da época, quando expõe a crítica à hegemonia do reconhecimento da produção artística de homens, enquanto a Arte produzida por mulheres era, de modo geral, diminuída, desprezada ou ignorada. Esta luta por visibilidade da Arte produzida por mulheres ainda é atual, como vemos, por exemplo, no trabalho das Guerrillas Girls, grupo de artistas ativistas feministas, que usam máscaras de gorila em público para manter o anonimato, visto que o importante é o evento, ação ou obra, não as pessoas que as fazem. A crítica se faz por meio dessa despersonificação e das ações artísticas, cartazes, livros, adesivos, vídeos e outros materiais produzidos pelo grupo, que expõem preconceitos de gênero e étnicos, bem como corrupção na política, arte, cinema e cultura pop (GUERRILLAS GIRLS, 2019).

É importante compreender que a pesquisa autobiográfica, independente de partir de uma narrativa pessoal ou daquela apresentada por múltiplas vozes confundidas com o discurso de artista, requer uma posição política e social que assuma um papel crítico. A investigação autobiográfica é uma tentativa de apontar para representação de um sujeito particular que contém, em suas diferenças, aspectos universais, capaz de conectá-lo com os demais. É o que Bernstein (2010, p. 102) chama de "[...] identidades-em-diferença, onde qualquer identificação é possível, e que um sentido de identidade comunal pode ser alcançado". Assim, ainda que a resposta dada pela artista em sua ação guarde justificativas com acontecimentos que lhes são particulares e pessoais, é possível que sua narrativa se conecte com as demais pessoas que partilharem da experiência performativa, promovendo identificações em diferentes níveis.

A cronologia dos estudos autobiográficos em performance realizados por artistas mulheres aponta para diversas e representativas produções, que destacam o papel da mulher na sociedade e a sua presença crítica na vida e na Arte. Assim, memórias, experiências pessoais e coletivas, relacionadas a temáticas do corpo, de violência de gênero, de sororidade, de

\section{POLÊM!CA $\mid$ LABORE}

Polêmica - Revista Eletrônica da Uerj - Rua São Francisco Xavier, 524, $1^{\circ}$ andar bloco D, sl.1001 • Tels.: +55 21 2334-4088 / 4087 • http://www.e-publicacoes.uerj.br/index.php/polemica/index http://www.labore.uerj.br • laboreuerj@yahoo.com.br 
maternidade, entre outras que permeiam o universo feminino, passaram a ser retratadas nas produções artísticas de modo a dar visibilidade para estas questões e travar embates em dimensões políticas e sociais.

Expoente na atualidade como artista visual que fala sobre o feminismo a partir de produções em diversas linguagens plásticas, como grafite, fotografia, escultura, criação de objetos, instalações e performance, Panmela Castro aparece no cenário nacional para contestar o pensamento binário e heteronormativo hegemônico, bem como para usar a Arte em favor da defesa dos direitos das mulheres, especialmente relacionado à violência doméstica.

Referência nacional na Arte do grafite, Panmela também conhecida como Anarkia Boladona, nasceu em 1981 no Rio de Janeiro e carrega uma biografia dolorida, com vestígios de um período perturbador no qual a artista sofreu diversos episódios de violência doméstica, desferidas por seu antigo parceiro, que inclusive a espancou e a manteve refém, até que ela conseguiu ser resgatada pela família e romper o relacionamento. Tentou também acessar a justiça em busca de apoio e proteção, mas seu caso, até então, não obteve nenhuma resposta legal. Diante da impunidade e insegurança, Panmela encontrou no grafite o caminho para seu retorno à Arte, apoiada por um grupo de amigas, com o qual começou a traduzir em murais sua história e a sua luta pelo fim da violência doméstica.

Com temas relacionados à sexualidade feminina, igualdade de gênero e direitos das mulheres, a artista passou a se destacar por seu trabalho ativista na Arte, ampliando sua atuação na defesa dos direitos das mulheres, por meio da fundação da Rede NAMI, em 2010 - ONG formada por mulheres que têm como objetivo utilizar a Arte para promover os direitos das mulheres, o fim da violência doméstica e conduzir para uma real transformação sociocultural (CASTRO, 2016).

Na vídeo-performance "A noiva” (2019), por exemplo, Panmela aparece vestida de noiva, segurando a saia do vestido, quase imóvel, em frente a um paredão, aonde é possível escutar as ondas do mar e o vento. Em dado, momento, ela acende um fósforo e ateia fogo à saia do vestido. Ouve-se o barulho do fogo amplificado e ela, lentamente, retira o vestido, fica nua e o deixa queimar ao seu lado. Quando abandona o vestido em chamas, escuta-se um outro som característico: badaladas de um sino que se supõe vir de uma igreja.

Os elementos escolhidos pela artista remetem à instituição do casamento. A análise da produção, em consonância com a vida e a motivação de Panmela, abre espaço para a leitura do

\section{POLÊM!CA $\mid$ LABORE}

Polêmica - Revista Eletrônica da Uerj - Rua São Francisco Xavier, 524, $1^{\circ}$ andar

bloco D, sl.1001 • Tels.: +55 21 2334-4088/4087 • http://www.e-publicacoes.uerj.br/index.php/polemica/index http://www.labore.uerj.br • laboreuerj@yahoo.com.br 
casamento como uma instituição que aprisiona e segue um movimento cíclico, como as ondas do mar, que vêm e vão e que podem ter momentos mais intensos, como mais brandos e suaves.

A quase imobilidade da artista pode ser lida como amarras impostas por uma relação opressora como o casamento, sobretudo, se considerarmos os valores monogâmicos, heteronormativos e misóginos autenticados por tal instituição. Diante dessa prisão, a ação de atear fogo no vestido com ele no próprio corpo revela a violência que pode marcar a vida da mulher casada, como o risco de anulação de sua existência, que pode arder em chamas se não se libertar dessas amarras. No caso da performance, a liberdade chegou, anunciada pelo corpo nu e as badaladas do sino. Revela, ao final, a mulher em sua integridade, liberta, plena e nua, enquanto o casamento se desfaz em cinzas.

Outra obra da mesma artista, a "Vagina Dentada" (2018) - criada a partir do poema homônimo da artista - aborda a questão do corpo da mulher em relação à figura masculina. Na ação em questão, a artista desce uma escadaria com um vestido de gala rosa, com uma longa cauda que marca o seu rastro. Ela se posiciona no centro da sala, quando um homem, com o corpo quase todo coberto de tecido preto, abre a parte de trás de seu vestido e começa a riscar/cortar a pele da artista com um bisturi. Panmela não esboça reação de dor ou incômodo e, ao final, termina de se despir e sobe as escadas nua, de cabeça erguida, como alguém que colocou voluntariamente seu corpo em risco, por escolha.

Assim como as palavras do poema, inspiração para a performance, a ação performática coloca Panmela no controle daquela situação, como a dona de seu corpo, ainda que em risco. Tal como as palavras tecidas por Castro (2018):

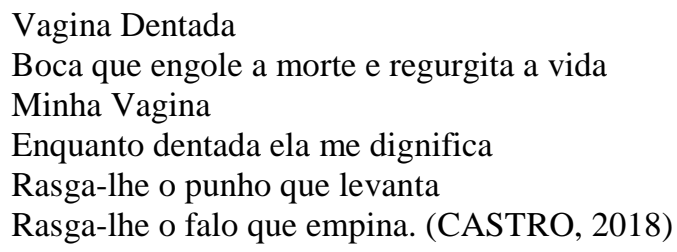

A ação em análise evidencia a potência da mulher livre, que se submete voluntariamente ao risco e à dor e que controla suas reações diante das adversidades. A mulher livre que escolhe o que fazer com o corpo e que se fortalece a cada talhada na pele.

Desde que a performance é compreendida enquanto linguagem artística, muitas artistas que tratam de temáticas ligadas ao feminismo buscam nela seu modo de expressão e mostram sua potência ao tratar de questões contemporâneas, políticas e sociais, além de abordarem

\section{POLÊM!CA $\mid$ LABORÉ}

Polêmica - Revista Eletrônica da Uerj - Rua São Francisco Xavier, 524, $1^{\circ}$ andar

bloco D, sl.1001 • Tels.: +55 21 2334-4088 / 4087 • http://www.e-publicacoes.uerj.br/index.php/polemica/index http://www.labore.uerj.br • laboreuerj@yahoo.com.br 
aspectos autobiográficos que intensificam o autoconhecimento e promovem a identificação com as espectadoras. A experiência disparada pela ação performativa culmina no inevitável aprofundamento do pensamento crítico, na produção de novos modos de existir e significar o mundo.

\section{Considerações finais}

O atual contexto histórico e social é crítico e nele observa-se uma escalada do conservadorismo e grandes retrocessos, com liberdades individuais e direitos cada dia mais questionados, invalidados, suprimidos, perdidos e usurpados, como exemplificado no início deste artigo. Por isso, torna-se urgente pensar estratégias de resistência para garantir a existência da educação plural, diante da ascensão de pensamentos ultrapassados que sustentam o machismo, racismo, homofobia e demais intolerâncias quanto às diferenças.

Avalia-se que promover informações de qualidade e a sensibilização por meio da Arte e da educação contribui para a compreensão e problematização dos contextos sócio-históricos e culturais. Assim, talvez, torne-se possível à educação encontrar meios de enfrentamentos às desigualdades e opressões sofridas socialmente.

A Arte Contemporânea produz diversas imagens que reforçam essa potência política, sobretudo no campo da performance, e pode ser uma alternativa para instigar o pensamento crítico, a liberdade e a criação de possibilidades de transformações no âmbito pessoal e coletivo. Nela, artistas encontram espaço para evocar a potência de ação e transformação por meio da Arte, especialmente quando abordam temáticas identitárias que refletem as lutas de movimentos sociais, como o movimento feminista, movimento negro e movimento LGBTQI+. Logo, contribui para o reconhecimento, a aceitação e valorização da existência de corpos políticos, bem como para a problematização de contextos sócio-históricos e culturais.

Por isso é importante aprofundar a pesquisa sobre a performance e suas relações com a educação, como campo de promoção de resistência, pluralidade e diferença. Assim, neste artigo, propôs-se analisar obras de artistas mulheres, que abordam diversas questões provocadas pelo movimento feminista, bem como a relação com a pesquisa autobiográfica e a importância do trabalho com objetos, memórias e imagens.

Há urgência - se tratando de um artigo escrito por uma artista feminista - em dar visibilidade para questões de gênero, fomentadas pelo feminismo, para reafirmar a liberdade

\section{POLÊM!CA $\mid$ LABORE}

Polêmica - Revista Eletrônica da Uerj - Rua São Francisco Xavier, 524, $1^{\circ}$ andar

bloco D, sl.1001 • Tels.: +55 21 2334-4088 / 4087 • http://www.e-publicacoes.uerj.br/index.php/polemica/index http://www.labore.uerj.br • laboreuerj@yahoo.com.br 
sexual, a autonomia, a segurança e o respeito às mulheres, assim como a todas as pessoas que se identificam com o feminino e por isso estão sujeitas a diversas violências e opressões.

As questões relativas ao feminino, embora já tenham alcançado espaços de discussão plurais e abertos, ainda são veladas em diversos contextos, pois esbarram em nossa estrutura social e nos preconceitos e limitações que ela sustenta. As mulheres ainda são tratadas como pessoas de segunda categoria, que estão disponíveis para servir e cuidar, que são detentoras de direitos cerceados, que têm seus corpos controlados e cujos desejos podem ser relegados em prol do (possível) bem estar de outrem.

Portanto, colocar em evidência a Arte feminista em performance pode ampliar a consciência individual e coletiva sobre a importância das pautas em defesa das mulheres e da equidade de gênero. Sabe-se que, historicamente, os conceitos e as imagens produzidas em Arte se transformam ao longo do tempo e refletem a construção dos paradigmas da sociedade, inclusive podem representar toda carga de opressão evocada por ela. Imagens que outrora eram naturalizadas e reforçavam preconceitos, hoje, em muitos contextos, são rechaçadas e desprezadas; não se sustentam publicamente sem gerar crítica como, por exemplo, o uso de blackface $^{7}$ e a exposição do corpo da mulher enquanto mercadoria.

Entende-se que a performance oportuniza espaços de troca de experiências, assim como possibilita compartilhar e viver com intensidade ações que podem afetar quem as experimenta, independente do lugar do qual se olha e vive. Se estabelece na produção de uma experiência em co-autoria, na qual tanto a(s) pessoa(s) que performa $(m)$ quanto quem assiste saem da zona de conforto e encontram a potência da vida. Propõe rupturas e culmina em possíveis transformações em instâncias, pessoais, políticas, artísticas, filosóficas e éticas, por exemplo.

A cada novo momento, a experiência se apresenta transformada e transformadora. Esse instante de vida (com)partilhado coloca o corpo num outro lugar, altera a percepção e aponta para memórias, imagens e sentimentos pessoais e coletivos, e que pode promover identificações entre as pessoas que partilham a experiência. A partir dessas identificações é possível construir novos conceitos e modos de (re)existir, de transitar por lugares nunca antes imaginados, de ressignificar experiências e encontrar caminhos, aspectos esquecidos, abandonados e desconhecidos.

\footnotetext{
${ }^{7}$ Significado oriundo do inglês, cuja palavra "black" refere-se a negro e "face" rosto, ou seja, aqueles artistas que pintam o rosto de preto para "interpretar" uma pessoa negra.
}

\section{POLÊM!CA $\mid$ LABORÉ}

Polêmica - Revista Eletrônica da Uerj - Rua São Francisco Xavier, 524, $1^{\circ}$ andar

bloco D, sl.1001 • Tels.: +55 21 2334-4088 / 4087 • http://www.e-publicacoes.uerj.br/index.php/polemica/index

http://www.labore.uerj.br • laboreuerj@yahoo.com.br 
Pensar a performance na educação e na Arte, buscar referências e imagens para alimentar o constante processo de ruptura com a normatividade, a não aceitação do que está posto e promover diferentes vivências performativas são maneiras de viver em trânsito permanente. É, por fim, reafirmar a existência como um modo de negar a vida ordinária, cotidiana, que engole, engessa e molda para manter as pessoas dóceis, fáceis de controlar e alienar, peças de uma grande engrenagem de manutenção do capital e, consequentemente, da estrutura social e econômica baseada na exploração e nas desigualdades.

\section{Referências}

ALMEIDA, Raquel de Q. Fake news: arma potente na batalha de narrativas das eleições 2018. Ciência e Cultura, São Paulo, v. 70, n. 2, abr./jun. 2018. Disponível em:

http://cienciaecultura.bvs.br/scielo.php?script=sci_arttext\&pid=S0009-67252018000200004. Acesso em: 24 abr. 2019.

BALISCEI, João Paulo. PROVOQUE: Cultura Visual, Masculinidades e ensino de Artes Visuais. Rio de Janeiro: Metanoia, 2020.

BARBOSA, Ana Mae. Arte-Educação no Brasil Realidade hoje e expectativas futuras. Estudos Avançados, [s.l.], v. 3, n. 7, p. 170-182, dez. 1989. Disponível em: http://www.revistas.usp.br/eav/article/view/8536. Acesso em: 18 out. 2018.

BERNSTEIN, Ana. A performance solo e o sujeito autobiográfico. Sala Preta, [s.1.], v. 1, p. 91-103, jun. 2010. Disponível em: http://www.revistas.usp.br/salapreta/article/view/57010. Acesso em: 25 mar. 2019.

BRECHT, Bertold. Poemas 1913-1956. Trad. Paulo César de Souza. São Paulo: Editora 34, 2000.

BOM-TEMPO, Juliana Soares. Performance e Educação: uma função-educador agenciada por intervenções no urbano. Educação, Santa Maria, v. 39, n. 3, p. 553-566, set./dez. 2014. Disponível em: https://periodicos.ufsm.br/reveducacao/article/view/14183. Acesso em: 25 mar. 2019.

BUTLER, Judith. Problemas de Gênero: Feminismo e subversão da identidade. Rio de Janeiro: Civilização Brasileira, 2003.

CARLSON, Marvin. Performance: Uma introdução crítica. Belo Horizonte: Editora UFMG, 2010.

CASTRO, Panmela. Portifólio da artista. Disponível em: https://panmelacastro.com. Acesso em: 14 mai. 2018.

COHEN, Renato. Performance como linguagem. São Paulo: Editora Perspectiva, 2007.

DAWSEY, John C. Turner, Benjamin e Antropologia da Performance: O lugar olhado (e ouvido) das coisas. Campos - Revista de Antropologia, [s.1.], v. 7, n. 2, p. 17-25, dez. 2006. Disponível em: https://revistas.ufpr.br/campos/article/view/7322. Acesso em: 25 mar. 2019.

FÉRAL, Josette. Por uma poética da performatividade: teatro performativo. Sala Preta, [s.l.], v. 8, n. 1, p. 197210, dez. 2008. Disponível em: http://www.revistas.usp.br/salapreta/article/view/57370. Acesso em: 27 abr. 2019.

\section{POLÊM!CA $\mid$ LABORE}

Polêmica - Revista Eletrônica da Uerj - Rua São Francisco Xavier, 524, $1^{\circ}$ andar

bloco D, sl.1001 • Tels.: +55 21 2334-4088 / 4087 • http://www.e-publicacoes.uerj.br/index.php/polemica/index http://www.labore.uerj.br • laboreuerj@yahoo.com.br 
MAIA, Dhiego. Bolsonaro propõe reduzir verba para cursos de sociologia e filosofia no país. Folha de São Paulo, São Paulo, 26 abr. 2019. Disponível em: https://www1.folha.uol.com.br/educacao/2019/04/bolsonaropropoe-reduzir-verba-para-cursos-de-sociologia-e-filosofia-no-pais.shtml. Acesso em: 7 maio 2019.

FRANCISQUETTI, Paula Patrícia Serra Nabas. Ana Medieta: atravessamentos em um coração desprotegido. 2009. 153f. Dissertação (Mestrado em Interunidades em Estética e História da Arte) - Universidade de São Paulo, São Paulo, 2009.

GLUSBERG, Jorge. A arte da performance. São Paulo: Perspectiva, 2009.

GUERRILLAS GIRLS. Site do coletivo. 1985-2019. Disponível em: https://www.guerrillagirls.com/\#open. Acesso em: 14 maio 2019.

GOLDBERG, RoseLee. A arte da performance: do futurismo ao presente. São Paulo: Martins Fontes, 2006.

GONÇALVES, João Ricardo; LEITÃO, Leslie; ARAÚJO, Marina; TEIXEIRA, Patrícia. Vereadora do PSOL, Marielle Franco é morta a tiros na Região Central do Rio. G1, Rio de Janeiro, 14 mar. 2018. Disponível em: https://g1.globo.com/rj/rio-de-janeiro/noticia/vereadora-do-psol-marielle-franco-e-morta-a-tiros-no-centro-dorio.ghtml. Acesso em: 7 maio 2019.

INSTITUTO BRASILEIRO DE GEOGRAFIA E ESTATÍSTICA - IBGE. Educação: anos de estudo e sexo. IBGE, 2015. Disponível em: https://brasilemsintese.ibge.gov.br/educacao/anos-de-estudo-e-sexo.html. Acesso em: 19 abr. 2019.

MATESCO, Viviane. Olhando o Interior Scroll Pergaminho Interior. Revista Performatus, ano.2, n. 8, jan. 2014. Disponível em: https://performatus.net/traducoes/interior-scroll/. Acesso em: 27 abr. 2019.

MENDIETA, Ana. Siluetas (1973-1980). Imagens da artista. Ana Mendieta, 2015. Disponível em: https://blogs.uoregon.edu/anamendieta/2015/02/20/siluetas-series-1973-78/. Acesso em: 28 de abr. 2019.

MOLINA, Ângela. Feminilidade e neodadaísmo. Desempenho e novas mídias. El País, 9 set. 2014. Disponível em: http://www.geifco.org/actionart/actionart01/nmP/perforwomances/CaroleeSchneemann/CaroleeSchneemann.htm . Acesso em: 1 jun. 2019.

PINTO, Célia Regina. Feminismo, história e poder. Revista Sociologia e Política, Curitiba, v. 18, n. 36, p. 1523, jun. 2010. Disponível em: http://www.scielo.br/pdf/rsocp/v18n36/03.pdf. Acesso em: 30 ago. 2019.

REDE NAMI. Arte Urbana e Direitos das Mulheres. Rio de Janeiro. Disponível em: https://www.redenami.com. Acesso em: 27 abr. 2019.

SANTOS, Elaine Reginas dos. Celeida Tostes: O barro como elemento integrativo na arte contemporânea. 2011. 205 f. Dissertação (Mestrado em Artes Visuais) - Faculdade de Artes, Universidade Estadual Paulista, São Paulo, 2011.

SCHNEEMAN, Carolee. Interior Scroll [Pergaminho Interior]. Revista Performatus, ano 2, n. 8, jan. 2014. Disponível em: https://performatus.net/traducoes/interior-scroll/. Acesso em: 27 abr. 2019.

SEREZA, Haroldo Ceravolo; BERTI, Lucas. Mapa da violência política registra ao menos 31 casos contra LGBTs em outubro. Ópera Mundi, 26 out. 2018. Política e Economia. Disponível em: https://operamundi.uol.com.br/politica-e-economia/53761/mapa-da-violencia-politica-registra-ao-menos-31casos-contra-lgbts-em-outubro. Acesso em: 25 mar. 2019.

SOUZA, Aguinaldo Moreira de. Dor e silêncio: performance e teatro sobre o holocausto nazista. Curitiba: Editora Appris, 2019.

\section{POLÊM!CA $\mid$ LABORE}

Polêmica - Revista Eletrônica da Uerj - Rua São Francisco Xavier, 524, $1^{\circ}$ andar bloco D, sl.1001 • Tels.: +55 21 2334-4088 / 4087 • http://www.e-publicacoes.uerj.br/index.php/polemica/index http://www.labore.uerj.br • laboreuerj@yahoo.com.br 
SOUZA, Marcos Leonardo. Educação no Brasil: Darcy Ribeiro e a crise da educação. Só Escola, 25 jul. 2018. Disponível em: https://www.soescola.com/2018/07/educacao-no-brasil.html. Acesso: 26 abr. 2019.

WORLD HEALTH ORGANIZATION. World health statistics 2018: monitoring health for the SDGs, sustainable development goals. Geneva: World Health Organization, 2018. Disponível em: https://apps.who.int/iris/bitstream/handle/10665/272596/9789241565585-eng.pdf?ua=1. Acesso em: 25 mar. 2019.

Recebido em: 19/09/2019.

Aceito em: 15/08/2021.

\section{POLÊM!CA $\mid$ LABORE}

